Marquette University

e-Publications@Marquette

Economics Faculty Research and Publications

Economics, Department of

4-1-1990

Cooter and Rappoport on the Normative

John B. Davis

Marquette University, john.davis@marquette.edu

Accepted version. Economics and Philosophy, Vol. 6, No. 1 (April 1990): 139-146. DOI. (C) 1990

Cambridge University Press. Used with permission. 


\title{
COOTER AND RAPPOPORT ON THE NORMATIVE
}

\author{
JOHN B. Davis
}

Marquette University

In a recent examination of the origins of ordinal utility theory in neoclassical economics, Robert D. Cooter and Peter Rappoport argue that the ordinalist revolution of the 1930s, after which most economists abandoned interpersonal utility comparisons as normative and unscientific, constituted neither unambiguous progress in economic science nor the abandonment of normative theorizing, as many economists and historians of economic thought have generally believed (Cooter and Rappoport, 1984). Rather, the widespread acceptance of ordinalism, with its focus on Pareto optimality, simply represented the emergence of a new neoclassical research agenda that, on the one hand, defined economics differently than had the material welfare theorists of the cardinal utility school and, on the other, adopted a positivist methodology in contrast to the less restrictive empiricism of the cardinalists.

In a later exchange with I. M. D. Little, Cooter and Rappoport support their view that nothing more than a shift in research agendas was involved in the ordinalist revolution by arguing that every conceptual framework operates persuasively in the particular way in which it "singles out objects for analysis, and designates how empirical information about them is to be sought, organized and understood" (Cooter and Rappoport, 1985, p. 1190). After the 1930s, most economists were simply persuaded that the new ordinalist research program did indeed single out valuable objects of analysis and strategies for their research. Moreover, they add, "once the normative nature of propositions is under-

The author is indebted to the editors, Daniel M. Hausman and Michael S. McPherson, and two anonymous referees of this journal for constructive comments on previous versions of this article. 
stood in terms of that body of doctrine from which they emanated, it then becomes apparent that material welfare economics is no more nor no less normative than ordinalist economics" (ibid.), and, consequently, that the change in research agendas did not abandon normative theorizing. Contrary to conventional wisdom, the scientific integrity of cardinal utility theory is not jeopardized by the cardinalists' willingness to make interpersonal utility comparisons, and the advent of ordinalism does not represent unambiguous scientific progress in the development of a value-free economics. The analytical revolution in neoclassical economic theory in the 1930s might better be said to represent the emergence of a less self-consciously normative manner of theorizing, although normative it remains in virtue of the persuasive way in which its new perspective operates.

In general, this characterization of the ordinalist revolution as a change in research agendas has much to recommend it. At the same time, however, to claim, as do Cooter and Rappoport, that because all theory is persuasive in its selective choice of objects of investigation and methods of analysis, all theory is thereby normative in nature, is to make all theory trivially and uninformatively normative. More seriously, to claim that a theory's perspective signals its normative content is to confuse normative propositions per se with simply value-laden ones. Yet, not only are the two types of propositions recognizably distinct, but the frequent ambiguities in a theory's value-laden propositions often permit a variety of competing inferences regarding that theory's normative content. ${ }^{1}$

Contrary to Cooter and Rappoport, then, a theory's perspective per se does not say much about its normative content. Thus, to say that the ordinalist revolution involved basic changes in theoretical perspective does little to explain how cardinalism and ordinalism lead to different normative commitments or how the ordinalist revolution involved a change in normative understanding. This is a disappointing conclusion to draw about an account that makes the transition from cardinalism to ordinalism largely a matter of changes in normative thinking, especially when there already exists a well-established literature concerning precisely those changes in normative thinking in neoclassical economics

1. Normative propositions per se make claims about what is right or wrong, just, fair, good for people, and so on. Value-laden propositions, or value-judgments, merely express controversial assumptions or ostensibly subjective points of view. Thus, in ordinalist theory, for example, the claim that agents' wants are nonsatiable expresses a value-laden proposition or value-judgment, while the proposition that individuals are better off in situation $x$ than in situation $y$ if and only if they prefer $x$ to $y$ expresses a normative proposition per se. The role the former pays in any particular inference regarding the latter depends on its interpretation, additional assumptions, among others, such that failure to distinguish the two types of propositions obscures the normative - in the most general sense - structure of the theory in question. 
that emerged with the ordinalist focus on Pareto optimality judgments. ${ }^{2}$ How is it, then, that Cooter and Rappoport come to be so misguided about the normative in the development of neoclassical economic theory?

I argue that Cooter and Rappoport and their opponents share a prevalent misconception of the normative. This emerges in the exchange between Cooter-Rappoport and Little, in which Cooter-Rappoport and Little, although disagreeing over the character of the ordinalist revolution, nonetheless make common use of key elements in the emotive theory of ethics. In the emotive theory, especially as popularized by A. J. Ayer in Language, Truth and Logic, normative propositions and simply value-laden ones (or value judgments) are treated interchangeably as subjective expressions of attitude used persuasively to affect opinion and belief in a noncognitive manner. Such propositions are contrasted with positive ones that lay claim to scientific objectivity by virtue of their susceptibility to empirical confirmation.

This is of some importance in the contemporary analysis of economics methodology, because to the extent that economists treat normative propositions as noncognitive, good economic theory then becomes synonymous with positive economic theory. Yet if, as suggested later, philosophers are right in dismissing the emotive theory as fundamentally mistaken, then many normative propositions may be no less objective than many positive ones. On this view, the elements of good economic theory need neither be necessarily positive nor necessarily empirically confirmable. Rejecting the emotive theory, economists would be able to appreciate the different roles normative propositions play in particular economic theories, rather than simply regard them as noncognitive expressions of attitude.

The exchange between Cooter-Rappoport and Little is a particularly convenient opportunity for raising these points, because of Little's own explicit association with the emotive theory of ethics. Indeed, in resisting the Cooter-Rappoport view that the persuasive way in which a perspective operates is central to the understanding of the normative nature of a theory, Little (1985, p. 1187) recalls his own account of the normative content of a theory. In his A Critique of Welfare Economics, he drew directly on the work of the most influential emotivist philosopher of the later 1930s and 1940s, Charles L. Stevenson. In Little's account, value-laden propositions are identified as value judgments by their use of attitudeinfluencing emotive language.

2. Of course, the conservative nature of Pareto recommendations, as a sort of "secondbest" utilitarianism, has long been appreciated since such judgments rule out tradeoffs in individual well-being via interpersonal utility comparisons that would increase overall social utility. But Pareto recommendations are also normatively controversial in being consequentialist, paternalist, and rights-ignoring. For a recent survey of some of these issues, see the introduction to Sen and Williams (1982). Of Sen's own many works in this area, see especially Sen (1979). 
Value judgments can, then, be recognized by considering what judgments are likely to influence people, not because they describe in colourless unemotive language facts which people already approve of, but because they describe facts in an emotive way, or because they are merely emotive and describe nothing at all. (Little, 1957, p. 70)

Furthermore, Little adds, following an influential article of Stevenson's (1938), to define, "whether implicitly or explicitly, an emotive word in such a way that one can or does apply it to something one wants persuasively described" is to give that work a "persuasive definition" (p. 69 ). Whether a proposition is value-laden is simply a matter of whether it employs emotive language.

Cooter and Rappoport respond, quite reasonably, that "the emotive force or persuasive nature of economic arguments" cannot be located "at the level of individual words or phrases, since these only have their sense within a particular conceptual framewwork" (1985, p. 1190). In their view, the "recommendatory terminology for expressing conclusions would seem . . . to be a secondary matter," since "the persuasive element of a body of doctrine" is associated with the perspective or framework in which ideas and data are presented (ibid.). Yet, it is doubtful that this critique amounts to more than a difference in emphasis. Little could allow that persuasive definitions gather their force because they presuppose the perspective of a particular theory. On the other hand, Cooter-Rappoport and Little agree that the perspective associated with a body of theory has persuasive impact, and that it is this persuasiveness that constitutes a theory's normative content.

Despite the fact that the emotive theory originally developed as more or less an adjunct to logical positivist views of science (Ayer, 1952, p. 20 ), few seem to appreciate that a critical posture toward the logical positivist ideal of science as preeminently positive and objective also entails reevaluation of one's views about normative thinking. Indeed, for many adherents of the logical positivist dichotomy between the positive/objective and the normative/nonobjective, abandoning the logical positivist conception of science as an exclusively objective endeavor led not to abandoning the view of the normative as noncognitive and nonobjective but to a view of all theory as nonobjective and ultimately normative. Ironically, then, although elaboration of the emotive theory was originally of secondary concern to the logical positivists, among many economists its assumptions have both outlasted and displaced those underlying the positivists' view of science.

How this came to be, it is fair to say, is probably tied up with the very strong terms in which Ayer and others originally characterized the normative in their effort to distinguish and elevate scientific thinking. Because the logical positivists believed first and foremost that experience 
was the test and control of objectivity in science, normative propositions, which were clearly neither descriptive of experience nor testable, were said to express feelings rather than make assertions. In Ayer's words:

We can see why it is impossible to find a criterion for determining the validity of ethical judgments. It is not because they have an "absolute" validity which is mysteriously independent of ordinary sense-experience, but because they have no objective validity whatsoever. If a sentence makes no statement at all, there is obviously no sense in asking whether what it says is true or false. And we have seen that sentences which simply express moral judgments do not say anything. They are pure expressions of feeling and as such do not come under the category of truth or falsehood. They are unverifiable for the same reason as a cry of pain or a word of command is unverifiable - because they do not express genuine propositions. (Ayer, 1952, pp. 108-9)

Since moral judgments are untestable, they cannot be regarded as objective. Accordingly, although the logical positivists' idea of an objective, positive science may be regarded illusory, normative thinking is still thought not to be part of any serious theoretical endeavor.

It might be argued, then, that the ordinalist revolution reflected not only a change in research agendas, but also a more or less conscious response to the emotivist view that moral dispute is a contest of influence in which individuals seek to persuade one another by expressing their feelings and attitudes. Ayer asserted that in moral argument one informs one's opponent of those facts that seem relevant to the issue at hand, but that if disagreement persists, then it must be concluded that "our opponent happens to have undergone a different process of moral 'conditioning' from ourselves" and "we abandon the attempt to convince him by argument" (Ayer, 1952, p. 110). Lionel Robbins, in his influential critique of interpersonal utility comparisons as normative, emphasized a similar theme in arguing that should an individual argue that some people are capable of experiencing more satisfaction from given incomes than others - a value judgment in his view - "we could not show he was wrong in any objective sense, any more than we could show that we were right" (Robbins, 1935, p. 140).

Thus, with these views commanding increasing attention in the 1930s and 1940s, welfare theorists such as Nicholas Kaldor (1939) and J. R. Hicks (1941) were faced with a dilemma. Although policy recommendation was a natural concomitant to economic analysis, that normative judgment in the popular view was deemed irremediably noncognitive seemed to preclude any place for policy in a discipline that aspired to become an objective science. In effect, the analytical and normative components of neoclassical theory seemed in conflict at the methodological level. Their response was to seize one of the horns of 
the dilemma by elaborating nonnormative, presumably objective compensation criteria for proposed policy changes. Compensation criteria merely require that those gaining from proposed policy changes only be able to compensate losers from such changes without the need to measure individuals' respective utilities in the process. Their successful elaboration would thus enable economists to make policy recommendations without making interpersonal utility comparisons, which Robbins had insisted could never be free of moral controversy. Hicks, a key proponent of this strategy, suggested its rationale in terms directly responsive to Ayer's view that moral controversy was irresolvable: "If $A$ is made so much better off by the change that he could compensate B for his loss, and still have something left over, then the reorganization is an unequivocal improvement" (Hicks, 1941, p. 111, emphasis added). Economics could thus retain its policy dimension because although welfare recommendations are indeed normative, nonetheless they appear sufficiently innocuous on this view that it might even be said that it is the objective, positive component of neockassical analysis that ends up driving all recommendation.

Compensation criteria, however, were ultimately abandoned by most welfare theorists as flawed and unworkable, ${ }^{3}$ thus leaving Pareto optimality judgments as essentially the sole policy instrument in neoclassical economics, and the methodological conflict between objective economic analysis and nonobjective normative judgment unresolved. Thus, in a later reaction to Robbins' arguments, Paul Samuelson retreats to something of a cultural relativist position to accommodate the unavoidable prospect of moral controversy. Asserting that Robbins is "undoubtedly correct" in his determination to exclude "ethical value judgments" from economic science, Samuelson instead calls for examination of the consequences of different such judgments, given the satisfaction of the usual Pareto conditions (Samuelson, 1947, pp. 219-21). That is, in allowing different moral judgments to enter welfare analysis much like data, although one cannot hope to reconcile different opinions regarding well-being, one can incorporate such value judgments in concrete policy recommendations that, given those assumptions, will not arouse controversy.

In this way, Samuelson, and the many other modern welfare theorists who follow him in this, not only adopts the new research agenda of neoclassical economics, as the account of Cooter and Rappoport has it, but also, it seems more importantly, appears to do so in good part because of a conviction that the normative is fundamentally nonobjective. It seems fair to argue, thus, that what ultimately underlies the ordinalist revolution in neoclassical theory is not so much a change in

3. See Mishan (1960) for a history of these developments. Compensation criteria, however, do continue to play a role in cost-benefit analysis. 
perspective on neoclassical theory as an acceptance of the logical positivist emotive theory view that normative thinking is nonobjective and noncognitive. The change in perspective in the ordinalist revolution, then, was less a matter of the way in which the new conceptual framework "singles out objects for analysis, and designates how empirical information about them is to be sought, organized and understood," and more a matter of a specific response to questions concerning the place of normative thinking in economic theory.

The emotive theory suffered decisive criticism in the immediate decade after its appearance, so that by the early 1950s, it was largely discredited among professional philosophers. ${ }^{4}$ The critics reasoned that although moral or ethical judgments are often used in a persuasive manner, and although they often express the attitudes and emotions of those who utter them, moral disagreement is still fundamentally a matter of rational argument about objective differences between right and wrong, the character of different moral goods, and so forth. Moral discourse, furthermore, presupposes a distinction between the expression of sentiments peculiar to particular individuals and the expression of sentiments approved by individuals generally. That is, moral judgments are typically made with the expectation that they will withstand some degree of rational scrutiny. They thus often possess an objectivity not unlike that conventionally associated with many positive propositions. Indeed, it has been argued that moral judgments are subject to at least two truth criteria, namely, ethical consistency and that such judgment involve something more than temporary attitude and commitment (Brandt, 1950, pp. 315-16).

These developments in philosophy cannot be said to have had much impact on economists, who continue to look on the normative much as Samuelson did. Cooter and Rappoport, then, might be said to have failed to explain the ordinalist revolution in a double sense. On the one hand, they uncritically adopt the emotivist view of the normative as a matter of persuasiveness. On the other hand, they also overlook an important dimension of the ordinalist revolution, the new view of normative thinking as nonobjective. This latter failing is not surprising, since that Cooter and Rappoport's commitment to the ordinalist view of normative thinking blinds them to the very different views of the normative held by the cardinalists, as well as to the disappearance of these more objective views in the research agendas of the ordinalists.

Finally, it should also be added that Cooter and Rappoport's methodology of change in research agendas is itself colored by their attachment to the ordinalist view of the normative as nonobjective. Although they recognize that the normative claims the cardinalists make are different from those of the ordinalists - Pareto optimality judgments 
supplant interpersonal utility comparisons in conventional policy recommendation - nonetheless, because they conceive of the normative as nonobjective, they cannot see in this change the abandonment of an objectivist conception for a subjectivist one. Thus, because Cooter and Rappoport see the change in neoclassical research agendas to be very much a normative matter, the change in research agendas must itself also be subjective or noncognitive. In this latter respect, they follow a view already widespread among philosophers of science. Yet, perhaps, their particular focus on the ordinalist revolution adds, almost by accident, an insight heretofore missing in philosophers' accounts of changes in research agendas in the natural sciences: the considerable appeal of the idea of a noncognitive change in research agendas to methodologists in economics ultimately itself derives from entrenched convictions about objectivity and subjectivity that themselves derive from the view of the normative that emerged from the ordinalist revolution.

\section{REFERENCES}

Ayer, Alfred J. 1952. Language, Truth and Logic, 2nd ed. New York: Dover.

Brandt, Richard B. 1950. "The Emotive Theory of Ethics." Philosophical Review 59:305-18.

Cooter, Robert, and Rappoport, Peter. 1984. "Were the Ordinalists Wrong About Welfare Economics?" Journal of Economic Literature 22:507-30.

. 1985. "Reply to I. M. D. Little's Comment." Journal of Economic Literature 23:118991.

Hennipman, Pieter. 1988. "A New Look at the Ordinalist Revolution: Comments on Cooter and Rappoport." Journal of Economic Literature 26:80-85.

Hicks, J. R. 1941. "The Rehabilitation of Consumers' Surplus." Review of Economic Studies 8:108-16.

Kaldor, Nicholas. 1939. "Welfare Propositions and Interpersonal Comparisons of Utility." Economic Journal 49:549-52.

Little, I. M. D. 1957. A Critique of Welfare Economics, 2nd ed. London: Oxford University Press.

- 1985. "Robert Cooter and Peter Rappoport, 'Were the Ordinalists Wrong About Welfare Economics?' A Comment." Journal of Economic Literature 23:1186-88.

Mishan, E. J. 1960. “A Survey of Welfare Economics, 1939-59." Economic Journal 70:197265.

Rappoport, Peter. 1988. "Reply to Professor Hennipman." Journal of Economic Literature 26:86-91.

Robbins, Lionel. 1935. An Essay on the Nature and Significance of Economic Science, 2nd ed. London: Macmillan.

- 1938. "Interpersonal Comparisons of Utility: A Comment." Economic Journal 48:635-41.

Samuelson, Paul. 1947. Foundations of Economic Analysis. Cambridge, MA: Harvard University Press.

Sen, Amartya. 1979. "Personal Utilities and Public Judgments: Or What's Wrong with Welfare Economics?" Economic Journal 89:537-58.

Sen, Amartya, and Williams, Bernard (editors). 1982. Utilitarianism and Beyond. Cambridge: Cambridge University Press.

Stevenson, Charles L. 1937. "The Emotive Meaning of Ethical Terms." Mind 46:10-31.

1. 1938. "Persuasive Definitions." Mind 47:331-50.

- 1945. Ethics and Language. New Haven: Yale University Press.

Warnock, Mary. 1960. Ethics Since 1900. London: Oxford University Press. 